\title{
Crowdfunding, Efficiency, and Inequality ${ }^{\mathrm{a}}$
}

\author{
Hans Peter Grüner $\quad$ Christoph Siemroth ${ }^{\mathrm{c}}$
}

January 15, 2018

\begin{abstract}
We show how decentralized individual investments can efficiently allocate capital to innovating firms via equity crowdfunding. We develop a model where consumers have privately known consumption preferences and may act as investors. Consumers identify worthwhile investments based on their own preferences and invest in firms whose product they like. In the presence of aggregate demand uncertainty, an efficient capital allocation is achieved if all groups of consumers have enough liquidity to invest. If some groups of consumers cannot invest, capital flows reflect preferences of liquid investors but not future demand. Comparing with traditional financing forms, crowdfunding in the absence of liquidity constraints can be superior unless traditional financiers are fully competitive and perfectly informed.
\end{abstract}

Keywords: Capital Markets, Crowdfunding, Crowdinvesting, Financial Markets, Information Aggregation, Wealth Inequality, Welfare

JEL Classification: D24, D31, D53, D63, D82, G20

${ }^{\mathrm{a}}$ We thank the editor, Juuso Välimäki, and two anonymous referees for valuable suggestions, and Philippe Aghion, Christoph Bertsch, Bruno Biais, Axel Börsch Supan, Peter Funk, Kerstin Gerling, Martin Hellwig, Johannes Hörner, Thorsten Hens, Eckhard Janeba, Ernst Maug, Benny Moldovanu, Jörg Oechssler, Martin Peitz, Nicola Persico, Elisabeth Schulte, Elu von Thadden, Anjan Thakor, Martin Weber, and seminar participants at various institutions for helpful comments and discussions. This paper is a strongly revised and extended version of the theoretical part of CEPR discussion paper 6750. The research was supported by the German Research Foundation (DFG) via SFB 884.

${ }^{\mathrm{b}}$ University of Mannheim, Department of Economics, L7, 3-5. 68131 Mannheim, Germany and CEPR, London. E-mail: gruener@uni-mannheim.de.

${ }^{\mathrm{c}}$ University of Essex, Department of Economics, Wivenhoe Park, Colchester, CO4 3SQ, UK. E-mail: christoph.siemroth@essex.ac.uk. 


\section{Introduction}

Crowdfunding is a new financing form for start-ups, entrepreneurs, artists, and even social organisations that draws on the masses (e.g., consumers, the general public) rather than a few professional financial intermediaries. Crowdfunding encompasses different funding models, in particular equity (as we consider in this paper) and debt contracts for investors, pre-order campaigns where consumers pay for the product upfront, and campaigns that rely on the good will of investors (i.e., donation or reward-based campaigns), and is conducted on Internet platforms (e.g., Belleflamme et al., 2015).

The aggregate funding volume of crowdfunding has grown considerably in recent years and may soon rival traditional funding forms. ${ }^{1}$ While crowfunding is attracting considerable interest in the financial industry and start-up scene, little is known about its allocative effects compared to other financing forms. This paper theoretically studies if and when equity crowdfunding can aggregate decentralized consumer information and efficiently allocate capital to new firms and technologies.

We consider a situation where a new firm requires funding to produce a new consumer product. One of the main problems in these early funding decisions is whether the new product or technology will be popular among consumers (and, hence, whether the firm will be profitable), i.e., there is aggregate demand uncertainty. From a social welfare perspective, if the product is going to be very popular, then it should obtain a lot of funding to meet the large future demand; if the product is only interesting to a small niche, then it should receive less or no funding. The novelty in crowdfunding is that a representative sample of potential consumers of the new product may participate in the funding decision of the firm - unlike in the case of classical venture capital financing, where a select few decide on funding products that they might never consume themselves.

Our main finding is that equity crowdfunding can resolve the demand uncertainty at the funding stage and attain a Pareto efficient capital allocation if all consumers are sufficiently liquid to invest. Crowdfunding works well because crowdinvestors can rely on their own consumption preferences when making their investment decision. In equilibrium, more interested consumers also invest more, thus the aggregate investment and hence the production of the new product can closely match future aggregate demand. The efficiency result is not merely driven by a simple pre-order mechanism, as consumers in equity crowdfunding are interested in a financial return and do not pre-order at the funding stage. Our finding is a very positive welfare result for crowdfunding, because it means that equity crowdfunding can achieve socially optimal funding decisions even if the properties of new products are not contractible at the funding stage, which disqualifies preorder crowdfunding and other more traditional pre-sales mechanisms. Our model also provides a theory that explains why investment behavior may be affected by personal consumption preferences for the products that these firms sell: Consumers that like the product tend to believe that the firm will have higher future revenues and will be more profitable.

We further find that a Pareto efficient capital allocation cannot generally be achieved if some

\footnotetext{
${ }^{1}$ Fortune (2014) predicted the global crowdfunding market could reach between $\$ 90$ billion and $\$ 96$ billion by 2025-roughly 1.8 times the size of the global venture capital industry then. According to some sources, this volume has been reached already: Crowdexpert (2015) reports on estimates from Massolution (2015) with a global fundraising of $\$ 34$ billion, the largest share going into peer-to-peer lending, and with equity and reward-based crowdfunding being of roughly equal size ( $\$ 2.5$ billion). Statista (2017) estimates the 2017 global crowdfunding at $\$ 195$ billion, with the largest amount going into peer-to-peer lending and about $\$ 13$ billion being invested via equity or reward-based crowdfunding.
} 
consumer groups are liquidity constrained, so that crowdinvestments reflect the preferences of some consumer segments, but not necessarily those of all consumers. Thus, depending on consumers' access to liquidity, capital may be misallocated, because consumer groups that are unable to invest still consume. Our analysis of the role of liquidity constraints is motivated by the empirical fact that financial wealth as a main source of liquidity is distributed far more unequally than income in most industrialized countries. ${ }^{2}$ Thus, a sizable share of households consume and thereby determine the success of new products and technologies, but do not have significant funds to invest and thus cannot participate in the funding decisions. The funding decisions may therefore be biased in a similar way as a poll is biased if certain voter segments do not participate.

Our analysis is based on a Bayesian investment game embedded in a dynamic general equilibrium structure with two periods (funding and consumption stage). The Bayesian game describes an investment process where shares of the firm are directly sold to many small consumers ("the crowd"), ${ }^{3}$ and the proceeds are used to increase production with a linear production technology. In the first period, consumers can invest in the new firm to increase their income for consumption, or in an outside option. In the second period, the firms sells its supply of the new good on a competitive goods market. Our main result of an efficient capital allocation holds for a broad class of preference distributions and utility functions, and also for debt rather than equity contracts. Moreover, we show that the efficient allocation is implemented in ex post equilibrium, where the informational requirements on investors about the types of others are mild compared to Bayesian equilibrium.

We compare crowdfunding to traditional financing forms such as venture capital and bank loans, which is usually funding from of finitely many strategic agents. These financing forms suffer from two drawbacks: market power and imperfect information about consumer tastes. Accordingly, large investors tend to underinvest, driving up goods prices and investment returns. Moreover, since they do not have access to the information of the entire crowd, they do not fully resolve the demand uncertainty that is inherent in startup funding decisions. Thus, traditional financing is efficient only if investors are fully competitive and perfectly informed. For these reasons, crowdfunding can be superior in startup financing, unless other virtues of $\mathrm{VC} /$ bank financing not considered in our model outweigh these drawbacks. Finally, we consider several extensions that largely confirm the robustness of our results, such as sequential observable investments during crowdfunding, nonlinear production technologies, and competition of crowdfunders and large professional investors.

Our model fits crowdfunding campaigns where firms primarily seek funding to expand production and meet demand. Consider three examples out of many on the platforms specializing in equity crowdfunding. The fashion designer firm "ilovegorgeous", for example, described their campaign on Crowdcube in the UK as "raising to fulfil customer demand by launching a boyswear

\footnotetext{
${ }^{2}$ Sixty percent of American households possessed almost no financial wealth (one percent of total financial wealth), while they held about 22 percent of total income late last century (Wolff, 2002). More recently, Saez and Zucman (2014) found that the bottom 90 percent of American households owned about 23 percent of wealth, but received 60 percent of income in 2012. A similar disparity of income and wealth distributions can be observed in many other countries (Davies et al., 2011). Moreover, according to Piketty (2014), the inequality of the wealth distribution increased over time in several industrialized nations.

${ }^{3}$ This kind of crowdinvesting differs from traditional forms of financing such as IPOs, where typically a predetermined share of the firm is sold to larger institutional investors, with assistance of an underwriter. Unlike IPOs, our crowdinvestment process does not determine a share price; rather, crowdinvestors invest an amount of capital and are entitled to a share of firm earnings in proportion to their investment. Otherwise both forms are similar in that equity shares are sold.
} 
collection." The firm sold $15 \%$ of its equity and obtained about $233 \%$ of the funds it initially asked for. This example highlights that pre-order crowdfunding may not always be suitable, since the new collection had not even been designed. "Kumpan" manufactures electric scooters and sought funding to "expand [...] and meet demand for emission-free mobility" on Companisto in Germany. It offered about $3 \%$ equity, and obtained twice as many funds as targeted. Finally, the US craft beer brewery "Mine Shaft Brewing" (MSB) sought funding to expand production capacity on the US platform Crowdfunder. In their pitch MSB cites a distributor saying "If MSB was producing now [we] would want you in UT, WY, NM", suggesting that limited production capacity was the only obstacle to profits. MSB did not meet their funding goal, perhaps because the general public was not yet allowed to invest by the regulator, ${ }^{4}$ which may have had similar consequences as the liquidity constraints in our model.

Our paper shows that funding decisions are different when the wealthy invest instead of liquidity-constrained consumers. To the best of our knowledge, this link between consumer preferences, wealth and investment has not yet been addressed in empirical research. Still, there is some anecdotal evidence that it plays a role in practice. On the one hand, there are cases where firms successfully turned to the crowd after failed attempts to get financing from traditional financial intermediaries. One such example is 'Good \& Proper Tea', which sells quality tea from a customized van turned into a tea bar. The founder was unable to secure more than two thirds of the necessary funding from conventional sources, but managed to obtain more than the remaining gap via crowdfunding (Guardian, 2014). ${ }^{5}$ On the other hand, there are also examples where wealthy investors' personal views and preferences seemed not to be aligned with the general customer base, possibly leading to inefficient funding decisions. A case in point is the German Luxury fashion label Escada, which had seen its best days in the 1980s when it provided red carpet dresses for Hollywood actresses. In 2009, however, Escada's dresses were widely perceived as out of fashion and the company had to file for insolvency (Handelsblatt, 2009). In the same year, the firm was saved by Megha Mittal, daughter in law of billionaire Lakshmi Mittal, whose first act as a CEO was to shop in her own store, taking advantage of the employee rebate. Six years later, the company was again in distress due to unsatisfactory sales (Handelsblatt, 2015). ${ }^{6}$

\subsection{Related literature}

It is a fundamental insight in financial economics that asset markets may (under certain conditions) efficiently aggregate decentralized information about relevant fundamentals. This paper contributes to this literature, arguing that a simple investment mechanism can efficiently aggregate

\footnotetext{
${ }^{4}$ In the US, members of the general public had been excluded from investing in start-ups and small enterprises until the Jumpstart Our Business Startups (JOBS) Act, Title III - specifically aimed at enabling equity crowdfundingwent into effect in May 2016. Before May 2016, only accredited individuals exceeding a certain income or asset threshold were allowed to invest.

${ }^{5}$ An alternative reason why this project was not funded by traditional financiers could be that they knew something about the product or entrepreneur that the crowd did not know.

${ }^{6}$ Of course, to some extent this example may also have been a case of changing consumer demand for the product which was not recognized by the wealthy funder The fact that professional (and typically wealthy) investors may find it difficult to predict the relevant behavior and preferences of other population groups has recently also been noted within the financial community itself. In an attempt to explain the markets' failure to predict the outcome of the British EU-exit referendum, Nicholas Colas, chief market strategist at New York brokerage Convergex, argues that "[t]here are two halves of America that do not talk to each other. Asset owners do not understand what those people who do not have wealth think about the world" (Financial Times, 2016).
} 
information about future demand even when forward markets for innovative products are missing. In equilibrium individuals invest in the products they like to consume. A simple linear example and some first empirical evidence for preference related investment choices can be found in an earlier version of this paper (Grüner, 2008). The present paper generalizes this theoretical analysis, studying in detail the distributional, technological and institutional conditions for efficient information aggregation, and it specifically adresses equity crowdfunding as a funding mechanism.

Several recent empirical studies investigate the determinants of fundraising success on crowdfunding platforms (e.g., Agrawal et al., 2011; Ahlers et al., 2012; Mollick, 2014; Li and Martin, 2014). Agrawal et al. (2014) and Belleflamme et al. (2015) review the first empirical findings. According to Agrawal et al. (2014), early results suggest that crowdinvesting can replace traditional sources of financing, just as we find in our model. They also remark that, when investments are linked to and motivated by an earlier access to the product, financing by the crowd may be able to provide information about demand to the entrepreneur that would not be available from venture capitalists.

An emerging formal literature studies information aggregation by pre-order crowdfunding mechanisms (Chang, 2015; Chemla and Tinn, 2016; Ellman and Hurkens, 2015; Schwienbacher, 2015; Strausz, 2016). A pre-order crowdfunding scheme operates like a set of forward transactions that are all made conditional on the aggregate volume of purchases. This means that the pre-order purchases realize only if investors pledge enough money in the aggregate. The entrepreneur can use the product price and the funding threshold to extract information from customers that is useful for the investment decision. ${ }^{7}$ With binary consumer types efficiency may be reached. ${ }^{8}$

The present paper instead considers an equity crowdfunding mechanism that can be used even when pre-order transactions are not feasible. Thus, our model-and equity crowdfunding more generally - allows agents to fund projects even if they have no interest in acquiring the product, because the investment goal is a financial return and not consumption. Indeed, we show that consumers who are not interested in the product may invest in the project in the inefficient equilibria (i.e., given liquidity constraints or nonlinear production technologies, see section 4.2), but interested consumers endogenously emerge as the only investors in the absence of the frictions. Funding by non-consumers of the good is a new aspect not captured by the pre-order crowdfunding models.

Regarding another difference, equity crowdfunding is viewed as more suitable for bigger projects: "Equity crowdfunding is perfect for companies that are looking to raise more capital than those that choose a rewards-based approach. These companies are typically seeking sums higher than

\footnotetext{
${ }^{7}$ Agrawal et al. (2014) and Belleflamme et al. (2014) made this point informally. Ellman and Hurkens (2015) study how crowdfunding can be used for market testing. Chang (2015), Chemla and Tinn (2016), and Strausz (2016) focus on the trade off between information gathering aggregation and incentives when the entrepreneur can embezzle the funds. Belleflamme et al. (2014) investigate whether an entrepreneur should rather use pre-order or equity-based crowdfunding. In their model, crowdinvestors are motivated by "community benefits" (utility from contributing) rather than investment return considerations as in our case.

${ }^{8}$ When the size of the investment is fixed and when there are no variable costs, the problem of designing a preorder crowdfunding scheme is identical to the problem of providing an indivisible public good with use exclusion. It is well known that efficiency and voluntary participation can generally not both be reached in this case because either some users may be (inefficiently) excluded in equilibrium, or individual contributions are too small (see, e.g., Gailmard and Palfrey, 2005 and the references therein). Efficiency results such as the introductory example in Strausz (2016) thus rely on a discrete distribution of consumer types, whereas our main result holds for continuous type distributions as well.
} 
$\$ 50 \mathrm{k}$ and have achieved social proof and gained enough traction to incentive their backers with the chance to own a small piece of their company as it grows" (Fundable, 2016). Moreover, we consider projects which mainly require funding for production or expansion, whereas the above studies consider projects that require funding to start (i.e., focus on fixed costs). Finally, we further highlight the role of the wealth distribution on funding decisions and include large professional investors in an extension, neither of which is considered in this literature.

Our extension with professional investors relates to the literature comparing market-based and bank-based financial systems (for a review, see Allen and Gale, 2001). Like us, Allen and Gale (1999) consider the problem of financing new technologies, but provide an alternative explanation why market finance (the analogue to our crowdinvestment) might emerge instead of financial intermediation. They show that sufficiently strong diversity of opinion among traders will favor market finance over intermediation, because an intermediary is more likely to make a suboptimal decision from the perspective of investors. In contrast to their model, our analysis focuses on the effect of the investor information and wealth distribution rather than diversity of opinion on the efficiency of capital allocation and the extent of financial intermediation.

It has also been noted that initial public offerings can aggregate useful information about the future success of projects (e.g., Benveniste and Spindt, 1989). The present paper studies the case where this information concerns the attractiveness of a firm's products for a population of consumers who also act as investors.

Finally, our contribution is related to a large literature that studies the effects of wealth inequality on allocative efficiency and in particular on the functioning of capital markets. A non-exclusive list is Aghion and Bolton (1997), Banerjee and Newman (1993), Banerjee (2010), de Mesa and Webb (1992), Galor and Zeira (1993), Grüner (2003), Grüner and Schils (2007), and Piketty (1997). All these papers emphasize the link between credit market imperfections and agents' investments into private production possibilities. Investors with little wealth either do not get credit for their individual investment projects, or they only get credit at a higher interest rate. This is why the distribution of wealth has macroeconomic implications. In the present paper, we instead consider the link between inequality of the wealth distribution and the investment in firms/technologies seeking funding. Moreover, a major difference of our model compared to existing incomplete markets models is that agents hold private information about consumption needs, which is also a signal about the realization of relevant aggregate uncertainty.

\section{Equity crowdfunding: The baseline model}

\subsection{Consumers and endowments}

Consider an economy which is populated by a continuum of consumer-investors indexed by $i \in$ $[0,1]$, who we will also call 'crowdinvestors.' Each consumer has an initial endowment $w_{i}$ of funds available for investment in period 1 ("liquid wealth") and receives an exogenous income $y_{i}>0$ in period 2. Consumers have no access to credit so that their liquid wealth is the only source to finance investments. Income $y_{i}$ and wealth $w_{i}$ are measured in monetary units. Individuals consume in period 2 and use the capital market to increase their income in period 2. They can invest any positive amount of their wealth in the firm producing the new good or in an outside option at the 


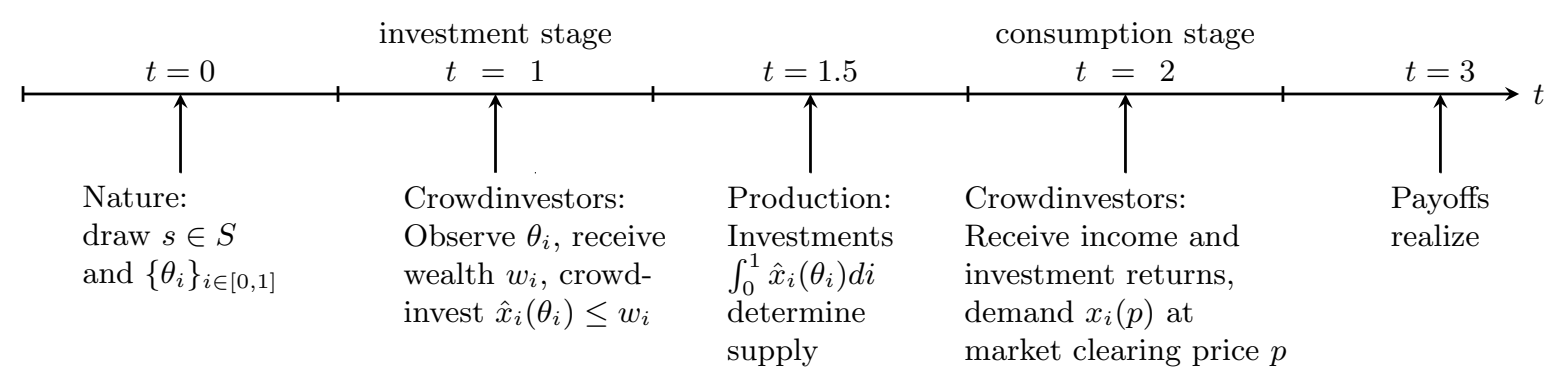

Figure 1: Timing of the model.

riskless rate $R$, i.e., one unit invested in period 1 turns into $R$ units in period 2 . The riskless rate $R$ is exogenously given. In period 2 , two consumption goods are available: consumption $c$ at a normalized price of 1 and the novel consumption good $x$. This timing is shown in Figure 1.

The utility function of consumer $i$ in general terms is

$$
u_{i}\left(c, x ; \theta_{i}\right)
$$

in consumption of $c$ and the novel good $x$ with parameter $\theta_{i}$, which can capture taste differences between consumers. We assume monotonicity and continuity for $u_{i}$ :

$$
\begin{aligned}
& u_{i}\left(c, x ; \theta_{i}\right)>u_{i}\left(c^{\prime}, x ; \theta_{i}\right) \text { for all } c>c^{\prime} \geq 0, u_{i}\left(c, x ; \theta_{i}\right) \geq u_{i}\left(c, x^{\prime} ; \theta_{i}\right) \text { for all } x>x^{\prime} \geq 0, \\
& u_{i} \text { is continuous. }
\end{aligned}
$$

The strict inequality for $c$ in (2) implies that preferences are non-satiated. Continuity (3) guarantees that an optimum to the consumer demand problem exists. The parameter $\theta_{i}$ is private information of $i$. For each $i$, the type $\theta_{i} \in \Theta_{i}$ is distributed according to $\phi_{i}\left(\theta_{i} \mid s\right)$ depending on a state of the world $s$ with distribution $\sigma(s)$.

There is a spot market for goods $c$ and $x$ in period 2. But there is neither a credit market on which consumers may borrow against future income $y_{i}$ nor a pre-sale of the innovative good $x$. A credit market friction is key to our results because, on a perfect credit market, all consumers could borrow against their future income in order to finance investments in the new product. Still, the assumption of no credit markets is stricter than necessary and only made for simplicity here. ${ }^{9}$ Impossibility of pre-sales is an appropriate assumption if the innovative good $x$ has important features that are not contractible at the funding stage, which is the case for many of the investment projects financed by crowdinvestors. Thus, companies cannot finance their investments drawing on the current sales revenues and must rely on external funding.

\footnotetext{
${ }^{9}$ It is sufficient to assume a wedge between borrowing and saving rates due to credit market frictions (e.g., Galor and Zeira, 1993), because borrowing requires an excess return from investing in equilibrium, which is incompatible with an efficient capital allocation (Lemma 1). Thus, allowing borrowing in imperfect credit markets does not change our efficiency results.
} 


\subsection{Production and the Bayesian investment game}

There are $m>1$ firms which have access to a technology for the production of good $x$. Each firm produces according to the linear technology:

$$
F(X)=X
$$

where $F(X)$ denotes the produced amount (supply) of the novel good and $X$ the aggregate investment made in period 1. Each consumer $i$ may invest any amount $0 \leq \hat{x}_{i} \leq w_{i}$ in the firms producing the new good. At the time of investment, consumer $i$ knows his own type $\theta_{i}$ but not the state of the world $s$ nor the types of the other consumers. The total production of all firms is determined by the aggregate investment

$$
X=\int_{0}^{1} \hat{x}_{i} d i
$$

All firms act as price takers in period 2 and distribute profits to all shareholders according to their relative investment shares.

In period 2, consumers receive their exogenous income $y_{i}$ and the return on their riskless or crowd-investments. Let $\tilde{y}_{i}$ be the total budget available to consumer $i$ in period 2 . At a given spot market price of the novel good $p$, each consumer solves the following maximization problem:

$$
\begin{aligned}
& \max _{c, x \geq 0} u_{i}\left(c, x ; \theta_{i}\right) \\
& \text { s.t. } \tilde{y}_{i} \geq c+p x .
\end{aligned}
$$

For each $i$, denote the demand function given relative price $p$ and budget $\tilde{y}_{i}$ that solves (4) by $x_{i}\left(p, \tilde{y}_{i} ; \theta_{i}\right)$. The aggregate demand correspondence in state $s$ is therefore

$$
x(p, s)=\int_{0}^{1} \int_{\Theta_{i}} x_{i}\left(p, \tilde{y}_{i} ; \theta_{i}\right) \phi_{i}\left(\theta_{i} \mid s\right) d \theta_{i} d i
$$

In this paper, we will focus on the cases where aggregate demand (5) depends on the state of the world $s$. We will use explicit expressions for demand and distributions from section 2.4 onwards, but for now we think of the distribution of $s$ as aggregate demand uncertainty regarding the novel good $x$. Thus, ex ante, the novel product may be very popular among consumers or very unpopular, which is exactly the kind of demand uncertainty that venture capital firms face when deciding on whether to fund start-ups.

Since producing firms act as price takers on the product market in period 2, aggregate investment $X$ determines the good's price in equilibrium by equating aggregate demand and supply, $X=x(p, s)$. The market price $p=p(X, s)$ for the novel good depends on the realization of $s$ (affecting demand) as well as aggregate investment $X$ (affecting supply). The equilibrium return on investment in the production of good $x$ is the firm revenue share proportional to total investment, which simply equals the good's price,

$$
r=\frac{p(X, s) \cdot X}{X}=p(X, s) .
$$


An equilibrium combines a Walrasian goods market equilibrium in period 2 with a Bayesian Nash equilibrium of the investment game in period 1.

Definition 1. An equilibrium of the model consists of

i. a consumption plan $x_{i}(p)$ for each consumer,

ii. an investment plan $\hat{x}_{i}\left(\theta_{i}\right)$ for each consumer, and

iii. a relative price function $p(X, s)$ for $\operatorname{good} x$,

such that

i. the consumption plan solves (4),

ii. the investment plans form a Bayesian Nash equilibrium of the investment game and are chosen subject to the wealth constraints as best response to the strategies of all other consumers, taking into account the consumption plans and the relative price $p(X, s)$, and

iii. at price $p(X, s)$ the aggregate demand $x(p, s)$ for good $x$ (given in $(5)$ ) equals supply $F(X)$.

We save on notation by not including wealth $w_{i}$ in the investment plan $\hat{x}_{i}\left(\theta_{i}\right)$ or $\tilde{y}_{i}, \theta_{i}$ in the consumption plan, since these are already associated with the index $i$. Since each state leads to a unique aggregate investment, we can define a state price $p(s)$.

A crucial point in this model is that the aggregate demand uncertainty is not easily resolved by asking consumers for their preferences, as is in principle possible on crowdfunding platforms or elsewhere on the internet. In every finite sample of consumers, every consumer who is interested in the new product has an incentive to overstate his interest in order to increase production, thus lowering prices. Hence, crowdfunding can be viewed as a mechanism where expressing interest is costly. We investigate the possibility of costly market research explicitly in the online appendix; these results are summarized in section 4.3.

\subsection{Efficient crowdfunding}

The main question is whether crowdfunding can achieve an efficient capital allocation, so that the new product is funded more if there is more consumer interest in the population. The problem is aggregate demand uncertainty: If aggregate demand depends on the realization of $s$, then Paretoefficiency requires supply (production) to also react to the state $s$, which is difficult since preferences $\left\{\theta_{i}\right\}_{i}$ are private information. Given the linear production technology, for which one unit of the novel product $x$ has an opportunity cost of $R$ units of $c$, the Pareto-optimal aggregate investment is such that the good's market clearing price equals $R$ in every state, which would exactly reflect the technological constraints (i.e., the marginal rate of transformation).

Our main result in Proposition 1 states that equity crowdfunding with a linear production technology can achieve a Pareto-optimal allocation if no consumer is wealth constrained. This result does not depend on a specific utility function nor a specific distribution of $\left\{\theta_{i}\right\}_{i}$. The general idea is that each consumer invests an amount that depends on his own preferences (i.e., $\left.\theta_{i}\right)$. More specifically, every consumer invests the amount that is necessary to produce the quantity that he will later consume at a relative price of $R$. Thus, supply always matches the aggregate demand at a relative price of $R$ for every realization of the type profile $\left\{\theta_{i}\right\}_{i}$, which is Pareto-optimal. 


\section{Proposition 1.}

Suppose that all consumers have sufficient wealth $w_{i} \geq \sup _{\theta_{i}} x_{i}\left(p=R, \tilde{y}_{i}=w_{i} R+y_{i} ; \theta_{i}\right)$. Then there exists an ex post equilibrium where all consumers invest $\hat{x}_{i}=x_{i}\left(R, w_{i} R+y_{i} ; \theta_{i}\right)$ and consume $x_{i}\left(R, w_{i} R+y_{i} ; \theta_{i}\right)$. This equilibrium is Pareto-efficient.

Proof. See appendix.

According to Proposition 1, crowdinvestments can efficiently replace a missing forward market for good $x$ if all consumers have enough wealth. The more consumers are interested in the novel good, the more they invest in equilibrium, thus increasing production of the good. Consequently, firms do not have to convince third parties that their business idea is worth investing in; instead, the source of funding is consumers who already find the product attractive. Indeed, the feature that consumers are also investors in crowdfunding is key, because this allows investments to react to changes in consumer demand. The equilibrium ${ }^{10}$ also explains why crowdfunding success is a valuable signal to obtain alternative funding: "[E]ntrepreneurs often use success on a [crowdfunding platform] to signal their creditworthiness and, thereby, facilitate their access to bank loans or attract venture capitalists" (Belleflamme et al., 2015, p. 18).

Note that crowdfunding with debt rather than equity contracts would yield the same equilibrium outcome if all consumers hold enough wealth. A debt contract would promise a return of $R$ per unit and the firm can repay the investors as long as $p(s) \geq R$, which is always the case in the efficient ex post equilibrium. Thus, payoffs and allocations would be exactly the same as in the model with equity contracts.

It is also interesting that the efficient equilibrium in Proposition 1 reproduces the outcome of pre-order crowdfunding, even though there is no formal pre-ordering: Effectively, all consumers pay an amount $x_{i}\left(R, w_{i} R+y_{i} ; \theta_{i}\right)$ to the company in period 1 , which exactly covers the cost of producing their consumption bundle, and all consumers receive $x_{i}\left(R, w_{i} R+y_{i} ; \theta_{i}\right)$ units of the good in period 2. The additional 'transfers' in our model - returns on equity to the crowdinvestors and payment to the company when purchasing the good - cancel out exactly. Clearly, as this analogy shows, the efficiency result rests on the linearity of the production function. In the presence of nonlinearities, the resulting equilibrium would generally not be efficient anymore (see section 4.2).

\subsection{Equity crowdfunding and liquidity constraints}

Motivated by the wealth and income distribution statistics from the introduction, we will analyze situations where some consumer groups are liquidity or wealth constrained, unlike in Proposition 1. In this case, and in the other extensions of our baseline model, the analysis of equilibria becomes considerably more complex. In order to deal with these difficulties, we use a more specific setup with an explicit utility function and distribution of types that permits us to explicitly calculate demand functions and posterior beliefs. We also use this more specific setup because it

\footnotetext{
${ }^{10}$ The Bayesian Nash equilibrium of the investment game is also an ex post equilibrium. The concept of ex post equilibrium is considerably stronger than Bayesian equilibrium (e.g., Dasgupta and Maskin, 2000; Bergemann and Välimäki, 2002). An ex post equilibrium requires that every player's Bayesian strategy remains optimal even if he knew the type vector $\left\{\theta_{i}\right\}_{i}$ (i.e., the types of the other players). Thus, every ex post equilibrium is a Bayesian equilibrium but not vice versa.
} 
illustrates the problem of demand uncertainty better and allows us to generalize our analysis in other dimensions later.

Preferences are represented by the following utility function:

$$
u\left(c_{i}, x_{i} ; \theta_{i}\right)=c_{i}+\theta_{i} x_{i}^{\alpha}
$$

with $0<\alpha<1$. The parameter $\theta_{i}$ is private information of consumer $i$, with $\theta_{i} \in\{0,1\}$, i.e., consumers either derive utility from consuming good $x$, or they do not. Solving the maximization problem yields the individual demand for good $x$,

$$
x_{i}(p)=\left(\frac{\alpha \theta_{i}}{p}\right)^{\frac{1}{1-\alpha}}=\theta_{i}\left(\frac{\alpha}{p}\right)^{\frac{1}{1-\alpha}}, \theta_{i} \in\{0,1\} .
$$

Since producing firms act as price takers on the product market in period 2, aggregate investment $X$ determines the good's price in equilibrium according to

$$
p=\alpha\left(\frac{\bar{s}}{X}\right)^{1-\alpha}, \text { with } \bar{s}=\int_{0}^{1} \theta_{i} d i
$$

We assume that all consumers have enough income $y_{i}$ in Period 2 to buy some of the new product even if they do not have any liquid wealth, $y_{i} \geq\left(\frac{\alpha}{R}\right)^{\frac{1}{1-\alpha}}$ for all $i$.

Let all consumers $i \in[0,0.5]$ belong to a consumer group 1 and all consumers in $i \in(0.5,1]$ belong to a consumer group 2. There is aggregate uncertainty regarding the share of consumers in the population that would like to consume the novel good $x$. This aggregate demand uncertainty is captured by a state of the world $s=\left(s_{1}, s_{2}\right)$, where $s_{1}, s_{2}$ are independently drawn according to the distributions

$$
\begin{aligned}
& s_{1}=2 \cdot \int_{0}^{0.5} \theta_{i} d i= \begin{cases}\beta>1 / 2 & \text { with probability } \frac{1}{2} \\
1-\beta & \text { with probability } \frac{1}{2}\end{cases} \\
& s_{2}=2 \cdot \int_{0.5}^{1} \theta_{i} d i= \begin{cases}\beta>1 / 2 & \text { with probability } \frac{1}{2} \\
1-\beta & \text { with probability } \frac{1}{2} .\end{cases}
\end{aligned}
$$

Thus, $s_{j}$ is the share of consumers in group $j$ with $\theta_{i}=1$ and $\bar{s}=\left(s_{1}+s_{2}\right) / 2$ is the share of interested consumers in the population. Consequently, there is demand uncertainty because a majority $\left(s_{1}=s_{2}=\beta\right)$, a minority $\left(s_{1}=s_{2}=1-\beta\right)$, or half of the population $\left(s_{1} \neq s_{2}\right)$ may be interested in the new product. Note the subtle difference between $s$ (a tuple) and $\bar{s}$ (a scalar). In this setup, $\bar{s}$ summarizes everything about state $s$ that affects aggregate demand and thus prices (see $(9))$.

As before, Pareto-efficiency requires a good's price of $R$.

Lemma 1. Suppose aggregate liquid wealth fulfills $\int_{0}^{1} w_{i} d i \geq \beta(\alpha / R)^{\frac{1}{1-\alpha}}$ and the production technology $F(X)=X$ is linear. Then the capital allocation is Pareto-efficient if and only if aggregate investment is $X=\bar{s}\left(\frac{\alpha}{R}\right)^{\frac{1}{1-\alpha}}$. This outcome is realized in a market equilibrium if and only if the good's market clearing price is $p(s)=R$ for all $s$.

Proof. See Appendix. 
Consider again the case of sufficient wealth as in Proposition 1. As before, an efficient ex post equilibrium exists (Proposition 2, part $(i$.$) ). While there are multiple efficient equilibria, { }^{11}$ parts (ii.) and (iii.) of Proposition 2 show that all of the efficient equilibria are unique in the aggregate (i.e., in terms of capital allocation, prices, and investment returns). Moreover, one could imagine additional equilibria to the efficient ones if all consumers have sufficient wealth, but part (iv.) shows that there are no equilibria where the capital allocation is inefficient. Unlike the ex post equilibrium in Proposition 1, part (iv.) uses the details of the type distribution to pin down the beliefs of the investors in an inefficient equilibrium candidate.

Proposition 2. Suppose all consumers hold wealth $w_{i} \geq\left(\frac{\alpha}{R}\right)^{\frac{1}{1-\alpha}}$.

i. There exists an ex post equilibrium in which all consumers invest an amount $\hat{x}_{i}=\left(\frac{\theta_{i} \alpha}{R}\right)^{\frac{1}{1-\alpha}}$ in the capacity for the production of good $x$. This equilibrium is Pareto-optimal.

ii. The ex post equilibrium aggregate investment function $X(s)$ is unique.

iii. Every ex post equilibrium is efficient and every efficient equilibrium is an ex post equilibrium.

iv. An inefficient equilibrium does not exist.

Proof. See appendix.

The intuition that there is no inefficient equilibrium $(i v$.$) is as follows. If there were an inefficient$ equilibrium, then there would be at least one state where the return on investment exceeds $R$. Because the preferences of crowdinvestors contain information about the likelihood of such a stateit is more likely that others in the same group are interested in the good if $i$ is interested - they would best respond by increasing investment. Together, the two groups of interested consumers can remove any excess return, because they have enough wealth to arbitrage away mispricing.

Proposition 2 yields a strong model prediction: If all crowdinvestors have enough liquidity, then the capital allocation is efficient. Now we investigate the role of liquidity constraints in the functioning of equity crowdfunding.

The next result shows that an efficient capital allocation can be achieved if and only if all groups of potential consumers in the population have sufficient wealth. In particular, it is not enough that aggregate wealth in the population is large - the distribution matters. For example, group 1 may be wealthy enough to cover the necessary investments of both groups while group 2 has no wealth. But then the capital allocation would be determined solely by the preferences (i.e., $s_{1}$ ) and information of the wealthy group and not react to preference realizations in the poor group $\left(s_{2}\right)$. Thus, Pareto-efficiency can be attained if and only if all consumer groups have enough wealth to make production react to all preference changes via investments. The result focuses on the distribution of wealth if enough aggregate wealth is available in the population $\left(\int_{0}^{1} w_{i} d i \geq \beta(\alpha / R)^{1 /(1-\alpha)}\right)$.

Proposition 3. Suppose $w_{i}$ is constant within each group of crowdinvestors and $\int_{0}^{1} w_{i} d i \geq \beta(\alpha / R)^{1 /(1-\alpha)}$. Then there exists an efficient equilibrium if and only if consumers in each group hold enough wealth, $w_{i} \geq(\alpha / R)^{1 /(1-\alpha)}$.

\footnotetext{
${ }^{11}$ For example, since individual investors have zero measure, one could change the investment strategies of finitely many players without affecting the capital allocation.
} 
Proof. See appendix.

Proposition 3 demonstrates the novelty of crowdfunding: Unlike bank finance or start up finance via venture capital, funding decisions are not made by a few large agents or a privileged group, but potentially by a representative sample from the relevant consumer population. The key is that information must be collected from all consumer groups in order to achieve the efficient allocation. This is possible only if the aggregate investment from the given group reflects accurately the consumption need for the new good in that group. It is not crucial that all $\theta_{i}=1$ consumers invest the same amount; half of them could just invest twice as much while the other half does not invest. Thus, efficiency is consistent with some wealth inequality within a group, where types are drawn from the same distribution, but not with inequality across groups so that one group has insufficient aggregate liquidity.

\section{Comparison with traditional start up finance}

To understand whether crowdfunding adds value to an economy, we need to compare it to other more conventional financing forms. The main outside sources of funding for startups in terms of volume - after personal credit, savings and contributions from friends and family - are venture capital, business angels, banks, and crowdfunding (from US data in descending order, see Fundable, 2013; similar in the EU, see European Startup Monitor, 2016). ${ }^{12}$ In this section, we will contrast the major financing forms of venture capital, business angels, and banks with crowdfunding. All of these traditional financing forms have in common that a few large agents are providing the funds rather than a group of many of the eventual consumers of the good (the crowd, which behaves competitively). As this section shows, efficient investment is typically not achieved with these traditional forms, either because of strategic underprovision of funds to extract larger profits, or because the investors lack the combined knowledge of the consumers to predict the future demand for the new product. These two - market power and imperfect information - are the key frictions that crowdfunding might be able to overcome and improve welfare relative to the traditional startup financing forms.

Note that our model does not address other specific advantages of traditional finance such as knowledge transfers and monitoring that have been stressed in the literature (e.g., Diamond, 1984; Bernstein et al., 2016). Thus, our conclusions regarding the advantages of crowdfunding concern the problem of information aggregation that we focus on. Overall, our analysis suggests that crowdfunding can play a very useful role in consumer-oriented sectors and for products with a high degree of demand uncertainty, whereas the classical Diamond (1984)-argument suggests that banks or VC have other advantages in sectors requiring expert involvement and on-site monitoring.

According to Tirole (2006, p. 92) "[i]t is customary to identify four stages of equity financing. In the first stage, equity is held by one or several entrepreneurs. These entrepreneurs may in a second stage raise equity capital from a small number of investors through a private placement; alternatively, they may have a privileged relationship with a bank. In a third stage (which most firms do not get to ) the firm goes public in a initial public offering (IPO). Lastly, it may conduct secondary or seasoned public offerings (SPOs)." Based on this categorization, our analysis fits into

\footnotetext{
${ }^{12}$ Initial public offerings are typically not a source of financing at the early startup stage.
} 
the second stage: Investments from a small number of equity holders (such as venture capitalists or business angels) and bank credit.

In the following, we keep the setup of our model, but restrict consumers to invest in the outside option at a fixed rate of $R$ during the investment stage. They consume as before in the consumption stage. We then analyze the welfare outcomes when venture capital firms, angel investors, or banks provide the funds for production instead of the crowd.

\subsection{Equity: Venture capital and angel investors}

Both venture capital firms and angel investors take an equity stake early on in startups in order to make large profits in a relatively short amount of time, typically by selling off the equity after a few years, e.g., in a successful IPO. This business is very risky, as many new startups fail within the first few years without generating significant profits, so the investors expect high returns in case of success.

In this analysis, we treat both venture capital firms and angel investors as strategic "big" agents (as opposed to the "small" crowdinvestors), who buy an equity share in the company. ${ }^{13}$ Consumers are restricted to investing their wealth in the outside option at return $R$ (so they cannot invest in the new product), and consume in stage 2 as before. We add a traditional financial sector consisting of $N \in \mathbb{N}$ risk neutral venture capital firms (or angel investors), indexed by $j$, with exogenous large endowment $W_{j}>0$, who maximize expected investment returns. They can either make safe outside investments with return $R$, or they can invest in the new company to obtain equity with variable return.

We stick to the two consumer groups case that we discussed in the previous section, and we assume that all venture capital firms have the same information about the realization of $s$. This latter assumption is not necessary for our results and is purely made to streamline the exposition. We represent the information by two binary and independent signals about the preference realization in consumer groups 1 and $2, m \in\{1-\beta, \beta\}^{2}$. The signal quality is exogenously given by

$$
\begin{aligned}
\gamma & :=\operatorname{Pr}\left(m_{1}=\beta \mid s_{1}=\beta\right)=\operatorname{Pr}\left(m_{1}=1-\beta \mid s_{1}=1-\beta\right) \\
& =\operatorname{Pr}\left(m_{2}=\beta \mid s_{2}=\beta\right)=\operatorname{Pr}\left(m_{2}=1-\beta \mid s_{2}=1-\beta\right)>1 / 2 .
\end{aligned}
$$

Perfect information about the realization of consumer preferences in the market is $\gamma=1$, while any $1>\gamma>1 / 2$ is imperfect information about the realization of the preference distribution, so that the signal indicates a wrong state of the world with positive probability. We can think of the signals as information obtained from market research polls (which is noisier the smaller or the more unrepresentative the sample).

The investment of the venture capital firms in the new product is denoted by $f_{j} \leq W_{j}$, which may depend on their information $m$. As before, investments are made simultaneously, so that

\footnotetext{
${ }^{13}$ While these two sources are similar on the finance side, there are differences regarding their involvement in firm policy between venture capital firms and business angels that are not the focus of this paper; for example, venture capitalists tend to have more influence on firm decisions.
} 
overall investment is given by

$$
X=\sum_{j=1}^{N} f_{j}(m) .
$$

The firm distributes all of its revenues from selling the new good in stage 2 depending on the equity investment share, so the per unit return on investment is $p(X, s) \cdot X / X=p(X, s)$, the market clearing price of the good, as before.

The main difference to equity crowdfunding is that venture capital firms are "big" and consequently have market power, which they can use to maximize their expected profits. If $N=1$, so that there is only one venture capital firm, then it acts as a monopolist, otherwise we have an oligopoly outcome. The maximization problem of firm $j$, when investing $f_{j}$ at the opportunity cost of $R \geq 1$, and taking the actions of other firms as given, is

$$
\max _{0 \geq f_{j} \geq W_{j}}\left(\mathbb{E}_{s}[p(X, s) \mid m]-R\right) f_{j}
$$

The first order condition is therefore

$$
0=\mathbb{E}_{s}\left[p_{X}(X, s) \mid m\right] f_{j}+\mathbb{E}_{s}[p(X, s) \mid m]-R \Longleftrightarrow \mathbb{E}_{s}[p(X, s) \mid m]=R-\mathbb{E}_{s}\left[p_{X}(X, s) \mid m\right] f_{j},
$$

where $p(X, s)$ is given in (9), and

$$
p_{X}(X, s)=\alpha \bar{s}^{1-\alpha}(\alpha-1) X^{\alpha-2}<0 .
$$

Thus, first order condition (11) implies that venture capital firms aim to realize an expected price greater than $R$, since $p_{X}<0$. But from Lemma 1 we know the efficient outcome requires a good's market price $p(X, s)=R$ in every state $s$, so the outcome with funding from venture capital firms is Pareto inefficient. This is because venture capital firms withhold funding - which determines production and therefore supply of the new good - in order to drive up the market price of the good and maximize profits. In this sense, these financial agents behave very much like Cournot oligopolists, since their investments determine how much the firm can and will produce.

Because the source of the inefficiency is market power, it does not matter whether the venture capital firms are perfectly informed about the preferences in the market or not, i.e., whether $\gamma=1$ or $\gamma<1$. They withhold funding either way, thus leading to inefficiently low production of the new good.

Consider now venture capital firms that are competitive and have no market power $(N \rightarrow \infty)$, so that an individual venture capital firm does not affect the aggregate investment $X$ nor the supply of the good. In this case, the first order condition becomes

$$
\mathbb{E}_{s}[p(X, s) \mid m]=R,
$$

so venture capital firms expect no profit (relative to outside option $R$ ), and the competitive venture capital sector supplies enough funding for the good's market clearing price to be $R$ on average. But if their information is imperfect $(\gamma<1)$, then they cannot perfectly react to the state to achieve a price of $R$ every time, yet this is what is required for an efficient allocation (Lemma 1). 
In short, Pareto efficiency with venture capital firms can be reached if and only if the sector is competitive and information is perfect. Neither of these conditions appear to be very realistic, as venture capital firms are not small zero-profit enterprises, and because perfect knowledge of the preference distribution in the population is hard to achieve. Consequently, our analysis suggests that crowdfunding can be welfare improving, because, first, crowdinvestors are small and cannot exploit market power. And second, taken together they have perfect information about the preference distribution among consumers (which professional investors first have to obtain), because the crowd is the population of consumers. The following proposition gives the formal result.

Proposition 4. If venture capital firms are the sole source of financing, then there exists no equilibrium with efficient investment, unless venture capitalists have no market power $(N \rightarrow \infty)$ and are perfectly informed about the preference realization $(\gamma=1)$.

Proof. See appendix.

\subsection{Debt: Bank loans}

While banks make use of different contractual tools/arrangements than venture capitalists or business angels, debt financing can generally suffer from the same shortcomings as venture capital financing schemes: market power and a lack of information. In what follows we show that bank finance yields inefficient outcomes both when banking is non-competitive but also when imperfectly informed banks engage in Bertrand-type interest rate competition.

In line with Tirole (2006, Section 3.2.3), we interpret a loan agreement as a profit sharing contract under which the borrower must reimburse a fixed sum or else go bankrupt. In case of bankruptcy, the borrower repays what he has. As Tirole (2006, p. 119) notes, debt and equity contracts can generate identical payment streams when the technology is sufficiently simple. This is also the case in the present model with a monopolist bank where the optimal debt contract leads to a payment that never leaves any profits to the firm.

\subsubsection{Monopolist bank}

First consider a single risk neutral bank that is the only available source of finance for the innovative firm. The bank offers a contract $(K, r)$ which specifies credit $K \geq 0$ given to the firm and a repayment rate of $r \geq 0$ (i.e., the overall repayment is $K \cdot r$ ). The bank has full bargaining power and can dictate the terms (the firm always accepts the credit contract). In all states of the world, the total repayment is limited by the firm's revenue. We assume the banks available wealth $W>0$ is nonbinding, and it can either give credit to the firm or invest in the outside rate $R$.

As before, the state is the shares of interested consumers in groups 1 and $2, s \in\{1-\beta, \beta\}^{2}$. The bank receives the signal $m \in\{1-\beta, \beta\}^{2}$ about the state $s$ with precision $\gamma>1 / 2$.

For credit volume $K$ (which determines production and supply), the maximal good's price (and hence revenue per unit) is $\bar{p}:=\alpha\left(\frac{\beta}{K}\right)^{1-\alpha}$, the intermediate good's price is $p:=\alpha\left(\frac{0.5}{K}\right)^{1-\alpha}$, and the minimal good's price is $\underline{p}:=\alpha\left(\frac{1-\beta}{K}\right)^{1-\alpha}$. Because of full bargaining power, the bank can extract all revenues from the firm, by setting the repayment rate to the maximal possible revenue $r=\bar{p}$, and it is optimal for it to do so. The bank only has to decide how much credit to extend 
to the firm, which determines how much the firm will produce, and hence what the good's price and repayment per credit unit will be. The maximization problem of the bank with signal $m$ is therefore

$$
\max _{K \geq 0}\left(\mathbb{E}_{s}[p(X=K, s) \mid m]-R\right) K .
$$

It turns out that this is the exact same maximization problem that a single venture capital firm faces (see (10)), since the bank due to its bargaining power extracts all revenues just like a single equity holder. Thus, a single bank cannot yield an efficient outcome even if it is perfectly informed $(\gamma=1)$, because it acts as a monopolist and withholds funding to drive up the revenues and thus the repayment. This result follows from Proposition 4.

Corollary 1. If a single bank is the sole source of financing, then there exists no equilibrium with efficient investment.

\subsubsection{Multiple banks}

Next we consider the case of multiple banks $j=1,2, \ldots, N$ with $N>1$. Banks all have a nonbinding endowment $W_{j}>0$ (e.g., they can refinance at outside rate $R$ ). They can either invest in the outside option at return $R \geq 1$ or give credit to the new firm and receive a repayment specified in the credit contract.

The strategy of every bank $j$ is a credit contract $\left(k_{j}, r_{j}\right)$ giving credit $k_{j} \geq 0$ to the firm and specifying a repayment rate $r_{j} \geq 0$ (i.e., the overall repayment for bank $j$ is $k_{j} \cdot r_{j}$ ). Banks may grant different credit sizes $k_{j}$, but all debt has the same seniority, so in case the firm cannot repay everything that was promised, all banks receive the same repayment rate. Define the overall credit volume as $K:=\sum_{j=1}^{N} k_{j}$.

As an equilibrium requirement, we impose that all banks must make zero profits with their credit contracts in equilibrium, the firm accepts all credit contracts and the firm makes nonnegative expected profits. ${ }^{14}$ Moreover, to simplify the analysis, we restrict the analysis to those equilibria in which the firm makes no positive expected profits, i.e., all revenues are repaid to the banks. ${ }^{15}$

As before, the state is the share of interested consumers in groups 1 and $2, s=\left(s_{1}, s_{2}\right) \in$ $\{1-\beta, \beta\}^{2}$. As in the case of venture capital firms, we assume banks receive the same signal $m \in\{1-\beta, \beta\}^{2}$ about the state $s$ with precision $\gamma>1 / 2$.

Proposition 5. Consider the case where bank credit with $N>1$ is the sole source of financing.

$i$. For any $m$, there exists a unique $K(m)$ such that there are no firm earnings in equilibrium,

\footnotetext{
${ }^{14} \mathrm{~A}$ more extended model would specify how the firm selects among the offered credit contracts, and competition in the repayment rate would induce Bertrand-competition that precludes positive profits for banks. To keep this section focused, we will not extend the model this way but instead make zero profits an equilibrium requirement.

${ }^{15}$ In general, there are other equilibria where the firm will retain earnings. The zero profit condition is imposed for simplicity and does not drive the efficiency results. Indeed, any equilibrium with firm earnings must be inefficient, since banks require an expected repayment rate of $R$, and so they have to underinvest in order to ensure sufficient bank repayments and positive firm earnings.
} 
with

$$
\begin{aligned}
& K: \mathbb{E}_{s}[p(K, s) \mid m]=R \Longleftrightarrow K=K(m)=\left(\frac{\mathbb{E}_{s}\left[\alpha\left(\left(s_{1}+s_{2}\right) / 2\right)^{1-\alpha} \mid m\right]}{R}\right)^{1 /(1-\alpha)} \\
& \text { and } r_{j}=\bar{p} \forall j \text { and any }\left\{k_{j}\right\}_{j=1, \ldots, N} \text { such that } K=K(m) \text {. }
\end{aligned}
$$

ii. There exists no efficient equilibrium unless $\gamma=1$.

Proof. See appendix.

In other words, there exists a unique aggregate credit level $K(m)>0$ lent to the firm such that the firm does not retain any earnings. Since this aggregate credit level can be provided by any convex combination of the $N$ banks, there is a continuum of equilibria.

Since the banks engage in a kind of Bertrand-competition on the expected repayment rate $r_{j}$, it only requires two banks to compete away their market power. Thus, the only obstacle to an efficient investment is the limited information about the state $s$ of the banks. If they do not know the preference distribution among consumers perfectly (in order to accurately predict future demand for the product), then banks cannot provide the credit amount to produce the efficient supply of the new product.

\subsection{Trade-offs in the choice of financial systems}

Our negative results regarding the role of venture capital financing and bank credit can be readily generalized. Actually, all financing forms that rely on a finite number of large investors who, in the aggregate, hold less than perfect information cannot produce an efficient outcome. The reason is that any information aggregation mechanism can only make use of the imperfect information of this finite set of investors. In addition, as we have shown in the cases of venture capital and a monopolist bank, market power can prevent efficient outcomes.

The previous analysis of specific traditional financing forms has the virtue that it permits to identify the distortions generated by specific market forms and to compare those distortions to other - in particular wealth or liquidity related - distortions in crowdfunding. Consider for example the case of a fully wealth constrained group of consumers in section 2.4. A welfare analysis of crowdfunding must take into account the systematic over- and underinvestment of the wealthy group and compare it to the distorted investment of oligopolistic venture capitalists. As we have shown, wealth constraints work against crowdfunding, whereas imperfect information and a lack of competition between venture capitalists work in its favor. Thus, a sufficiently competitive venture capital sector with high quality information has an important role in startup finance if the wealth distribution prevents crowdfunding to unfold its full potential. In this sense, participation barriers of "the crowd" such as wealth constraints are a key impediment to reaping the benefits from the use of its dispersed information. When consumers are not wealth constrained, the model shows that a system that relies exclusively on venture capital as a funding source is less efficient than crowdfunding.

The comparison of crowdfunding with more traditional financing forms can in principle be used to guide the design of the financial system. However, since financial systems emerge and evolve endogenously, it is also important to understand how crowdfunding and large investors interact 
when crowdfunding platforms enter the financial system and compete with traditional financing forms. Based on our previous results, the analysis of this interaction is straightforward. A first interesting observation is that, when crowdfunding works efficiently, there is no scope for venture capitalists or banks to earn money from an investment since all state prices equal $R$ and there are no profits to be had. That is, the efficient crowdfunding equilibria from section 2.4 still exist.

Second, if strategic venture capital firms $(N<\infty)$ and crowdfunders may both invest in the new firm, then there exists no efficient equilibrium where venture capitalists invest. Suppose an efficient equilibrium with positive venture capital investment existed. Then the return on investment would be $R$ in every state. But then an investing venture capitalist could deviate by cutting his investment in half, and since he has market power, it would reduce supply and increase the good's market price above $R$ (which is also the return on investment). Thus, such a deviation is profitable and an efficient equilibrium where venture capitalists invest does not exist due to their market power. So clearly crowdfunding can be a valuable addition to startup finance even when directly competing with the traditional financing forms. In the extensions section, we elaborate on some of the coexistence questions further.

\section{Extensions and robustness}

This section summarizes various extensions of the model; the detailed analyses and proofs can be found in the online appendix.

\subsection{Sequential investments}

On most crowdinvestment platforms irreversible investments can be made in a given timespan. During this investment time frame, the current aggregate investment into a project is observable for potential investors. Thus, sequential and observable investments may allow crowdinvestors to learn something about the preferences of liquidity constrained consumers, and consequently adjust their investment to what they have observed. This could potentially alleviate the inefficiency problem due to wealth constraints that we discussed earlier. In order to study this problem, we extended the simultaneous investment game to a simple sequential two stage investment game, where aggregate investment from the first stage is observable in the second stage. The results we report here do not change if we allow more investment stages.

The first result in this sequential setting is that all equilibria from the baseline model can be translated to equilibria in this dynamic model with exactly the same outcomes. This can be seen quite easily: If nobody invests in the first investment stage, then the information in the second stage is exactly the same as in the simultaneous investment game. This result shows that the set of equilibrium outcomes is weakly larger in the sequential model.

Then the interesting question is whether the sequential investments allow for efficient equilibria that do not exist in the baseline model due to the possibility of learning from and reacting to the investments of others. Our second result is that such efficient learning equilibria exist if all consumers groups have some wealth to invest, so that they can "signal" the aggregate demand realization of their consumer group, and if aggregate wealth is sufficient. Thus, the possibility of sequential investments weakens the requirement on the wealth distribution compared to the 
baseline model with simultaneous investment (Proposition 3), where every consumer group needs to have a sufficient amount of liquid wealth. Now, with sequential investments, wealth can be distributed very unevenly as long as every consumer group has some wealth to signal in the crowdfunding campaign. Whatever one consumer group is missing, another can invest "on their behalf" after learning from earlier investments how much demand this constrained consumer group will have.

These efficient learning equilibria all have the same structure: Constrained groups invest early depending on their preference realizations, so that the first period aggregate investment is "fully revealing" or "separating" regarding the preference realization in these groups. Then other unconstrained groups invest later in response to what they learned from earlier investments (and their own preferences), which together leads to efficient investment and allocations.

Taking these two results together, the implication is that efficient and inefficient equilibria can coexist in the sequential investment model. Thus, the welfare prediction of the sequential model might not be unique. However, as a final result, we show that the efficient learning equilibriawhich require early investments of a positive mass of consumers - are in weakly dominated strategies, while equilibria with investments only at the last possible moment are not weakly dominated. This is because early investments could (off equilibrium) be very large, diluting the return on equity below $R$. Someone who invested early cannot react to such a development, whereas someone who waited for the last possible moment to invest can still react. Consequently, our analysis points out that there are incentives against investing early in crowdfunding campaigns. ${ }^{16}$ On game theoretic grounds, therefore, the welfare prediction of the simultaneous investment game is stronger.

Overall, the results from the sequential investment model are even more positive for crowdfunding compared to the simultaneous investment model, as learning from investments can allow for an efficient outcome which would not be achieved with simultaneous investments.

\subsection{Nonlinear production technology}

To investigate the role of the production technology, we generalize from the linear to nonlinear technologies with the production function

$$
F(X)=X^{\lambda}=\left[\int_{0}^{1} \hat{x}_{i} d i\right]^{\lambda}, \lambda>0
$$

which translates aggregate investment into supply of the good. $\lambda$ is a technology parameter, with $\lambda=1$ covering the linear case and $\lambda>1$ or $\lambda<1$ allowing for convex and concave production technologies, respectively.

We first show that the social optimum requires an investment that is nonlinear in the share of interested consumers if the production technology is nonlinear - unlike in the linear technology case. Second, we show that the nonlinearity in the production technology means that decentralized crowdinvestments will generally not yield an efficient outcome any more. One of the reasons is

\footnotetext{
${ }^{16}$ Indeed, in parimutuel betting - where as in our case the profits and losses are shared among all who invest-it is typically observed that bettors wait to place their bets until the very last moment in order to be able to react to new information (and not reveal their information to others), see, for example, Ottaviani and Sørensen (2009) and the references therein. Ebay is another context where strategic waiting for the last moment to act is common (Roth and Ockenfels, 2002).
} 
that crowdfunding - which linearly adds up investments of consumers - cannot match a nonlinear investment function for more than two states (shares of interested consumers).

However, one key effect of the baseline model still plays a role: If all consumer groups can invest, then the aggregate investment reacts strictly monotonically to the share of interested consumers in all consumer groups in equilibrium. If not all consumer groups can invest, then there is no such monotonicity of aggregate investment. Thus, even if the production technology is nonlinear, we still expect crowdfunding to be more efficient (in a utilitarian sense) if all consumer groups can invest, because investment reacts better to the state and should remove some variance from investment returns and prices. We confirm this intuition with two results. First, analytically, a scenario where all consumer groups can invest is better in terms of welfare for nonlinear technologies in a neighborhood around $\lambda=1$ by continuity. Second, numerically, we show that this ranking holds even for nonlinear technologies far away from $\lambda=1$.

In a more technical analysis, we find that both interested and uninterested consumers invest in equilibrium if the production technology is concave. This is in contrast to the linear and convex production technologies, where typically only the consumers invest that also want to consume the good. This result gives some predictions about which kind of consumers should invest depending on the production technology or product.

In summary, while crowdfunding is generally not efficient any more with nonlinear production technologies, it still works better if the information and funds of the entire crowd can be used, compared to cases where some consumer segments cannot invest. The reason is that crowdfunding can then aggregate the information of all consumers, so that investment and production better matches consumer needs.

\subsection{Large strategic investors and market research}

Most professional investors base their decisions on extensive research into companies and their markets. To further investigate whether professional investors can fix the inefficiency if not all consumers can participate in crowdfunding, we developed an extended model where large strategic investors and crowdinvestors coexist. Moreover, the professionals can obtain costly market research to learn something about the preferences of the consumers.

We first show that if no consumers are wealth constrained, then there exist efficient equilibria where only crowdinvestors but no professional investors provide funding for the firm. The reason for this is quite easy to see: In an efficient equilibrium, the return on investment is $R$, so professional investors are not willing to invest even more in the new firm. Consequently, if professionals and crowdfunders coexist, then crowdfunders take over all funding.

We next show that there exists no efficient equilibrium where professionals invest. This is because if such an equilibrium existed - with an investment return of $R$ in every state - then it would not pay for the professionals to buy market research and get informed. But if they are not informed, then investment cannot perfectly react to the state of the world. Thus, such an equilibrium does not exist. This result is similar to Grossman and Stiglitz (1980)'s classical result that there exists no (informationally efficient) equilibrium where traders acquire information at a cost, except we consider Pareto efficiency in a production economy and not (just) informational efficiency. 
Third, we show that if some consumer groups cannot invest, then the presence of professional investors cannot fix the inefficiency. The obstacles are the same as in our comparison section 3 with traditional financing forms: market power and imperfect/costly information. Thus, as argued above, professional investors can bring about an efficient allocation if and only if they behave competitively (which requires many of them, $N \rightarrow \infty$ ) and receive perfect information about the state for free, i.e., there is no imperfect information.

In summary, the crowdfunding results from our main section are robust even in the presence of strategic professional investors, so that an efficient capital allocation is achieved if and only if all consumer groups can participate in the crowdfunding campaign.

\section{Conclusion}

Recent technological advances and the widespread use of the internet made it possible to match a large amount of investors with projects or firms seeking funding at substantially lower cost. Thus, firms and projects that were previously too small to offer equity directly to the public, and therefore had to rely on financial intermediaries, now have access to the money and wisdom of crowds. Our results show that the improved access to financing from crowdinvestors may increase the efficiency of capital allocation for those small firms. Hence, our paper shows that crowdinvesting may be a valuable financial innovation which can improve social welfare.

Unlike in classical venture capital financing, the funding decisions in crowdfunding may be made by potential customers of the firm. For this reason, we find that equity crowdfunding can efficiently allocate capital to new firms if all potential consumer groups are wealthy enough to invest. However, wealth is more concentrated than income in most western nations, so that only those who are wealthy enough invest. In this case, firms with products favored by the wealthy will attract the most funding, but these are not necessarily the firms that meet the highest demand and need the most funding.

In a comparison with traditional startup financing - in particular venture capital and bank loans - we find that crowdfunding can improve welfare if all consumers are able to participate in the crowdfunding campaign. The two obstacles to efficiency of the traditional financing forms are market power, which these professional financiers use to extract more profits via an underprovision of funds, and imperfect information about consumer preferences. Both of these obstacles can potentially be overcome by crowdfunding, as the consumers are so numerous that they do not have market power and, as a whole, the crowd has perfect information about preferences if it consists of a representative sample of consumers. Still, banks and venture capital have a place in startup financing especially for projects requiring on-site monitoring.

In the present model, the quasi-linear utility function makes the crowdinvestors risk-neutral. A different channel that may lead to similar investment patterns as in our model consists in consumers trying to hedge against price increases of products they like. As one option, consumers could hedge by investing in the company making the product, because price increases also lead to higher returns on equity. An analysis investigating the impact of such a hedging motive would have to assume that investors are risk-averse and add a source of aggregate uncertainty that cannot be resolved by crowdfunding, leading to price risks. 
Our analysis generates several empirical predictions. First, all else equal, consumers invest more in firms whose products they like. This behavior should not (only) be driven by a sympathy for a brand name or the firm, but by the favorable information that the own preference for a firm's product contains. Separating these two channels is an empirical challenge. A first, basic test would be to verify the consistency of investment and consumption behavior of users of crowdfunding platforms. A second testable hypothesis is that liquidity constraints among potential consumers limit the scope of direct financing mechanisms such as crowdfunding (compared to intermediated finance) for certain products. Specifically, our theory predicts that the capital allocation for luxury products aimed at wealthy consumers may work even with very unequal wealth distributions in the population, because all potential consumers have sufficient wealth and income to invest and buy. Instead, information aggregation may not work properly when it comes to financing the production of goods aimed at less fortunate consumers, who consume but cannot invest. Accordingly, we would expect more efficient outcomes - e.g., measured by a lower return variance or fewer bankruptciesfor firms with products designed for more affluent customers. Third, and relatedly, our theory predicts that funding outcomes are on average more efficient when the wealth distribution of consumers better matches the income distribution. This relationship can in principle be tested with cross country distributional data. 


\section{Appendix}

Proof of Proposition 1. We go backwards from the consumption stage. Since $u_{i}$ is continuous, Berge's maximum theorem guarantees that a solution to the consumer demand problem $(4), x_{i}(p, \tilde{y})$, exists. In the consumption stage, a market clearing price $p$ determined by equating aggregate supply (determined by the candidate investment strategy profile) and demand $\int_{0}^{1} x_{i}\left(R, w_{i} R+y_{i}\right) d i=\int_{0}^{1} x_{i}\left(p, w_{i} p+y_{i}\right) d i$ is $p=R$ in all states $s$.

In the investment stage, every investor is indifferent between investing any $\hat{x}_{i} \in\left[0, w_{i}\right]$ given everybody else plays the equilibrium candidate. This is because the return on investment equals the market clearing price $R$, which atomistic individual investors cannot change by changing their own investment $\hat{x}_{i}$, and since $R$ is also the return on the riskless asset. Thus, there is no profitable deviation at the investment stage, and $\hat{x}_{i}=x_{i}\left(R, w_{i} R+y_{i}\right)$ is an equilibrium. It is furthermore an ex post equilibrium, since any change in the $\theta$-profile that induces a change in the aggregate demand function is exactly matched by a change in the aggregate supply given the equilibrium candidate strategy profile. Hence $p=R$ for all realizations of the $\theta$-profile so that $\hat{x}_{i}=x_{i}\left(R, w_{i} R+y_{i}\right)$ is always optimal.

We show Pareto efficiency by analogy: A Walrasian equilibrium allocation with the same production technology for profit maximizing and price taking firms (who know consumer preferences) is exactly the same as the ex post equilibrium allocation in our model. Hence, by the first welfare theorem and non-satiation of preferences, the ex post equilibrium is Pareto-efficient.

In the first welfare theorem setup, suppose there is one competitive profit maximizing firm with a production technology that turns $R$ units of $c$ into one unit of $x$. This exactly reproduces the opportunity cost of production and thus feasible production levels from our model. Then, given this production technology, a Walrasian market price for good $x$ is $p=R$. Suppose not, so that $p>R$ is the market price. Then the profit for each produced unit $x$ is $p-R>0$ (buying $R$ units of $c$ at price 1 and selling one unit of $x$ at price $p>R$ ). But given the constant returns to scale production technology, there is no profit maximizing production level, so this cannot be an equilibrium. Next, suppose $p=q<R$, then each produced unit of $x$ implies a loss of $q-R<0$, so that the firm does not produce $x$. Now we distinguish two subcases. First, if utility functions are such that aggregate demand at $p=q$ is positive, then this contradicts market clearing and $p=q<R$ cannot be a Walrasian equilibrium. Second, if utility functions are such that aggregate demand at $p=q$ is zero, then since $u$ is weakly increasing, aggregate demand will also be zero at $p>q$. In this case, any $p \geq q$, and in particular $p=R>q$, can be a Walrasian equilibrium price.

Now at a price of $p=R$ with budget $\tilde{y}=w_{i} R+y_{i}$ (which is the same budget as in the ex post equilibrium), the demand correspondence that maximizes utility for each $i$ is $x_{i}(p=R, \tilde{y}=$ $\left.w_{i} R+y_{i} ; \theta_{i}\right)$ by definition. Aggregate demand is therefore $\int_{0}^{1} x_{i}\left(p=R, \tilde{y}=w_{i} R+y_{i} ; \theta_{i}\right) d i$, and since firms have a constant returns to scale production technology, they can satisfy aggregate demand with equality at zero profits given $p=R$. Hence, the allocation $\left(c_{i}, x_{i}\right)=\left(\tilde{y}-R x_{i}(p=R, \tilde{y}=\right.$ $\left.\left.w_{i} R+y_{i} ; \theta_{i}\right), x_{i}\left(p=R, \tilde{y}=w_{i} R+y_{i} ; \theta_{i}\right)\right)$ for all $i \in[0,1]$ with $p=R$ is a Walrasian equilibrium, and it is the same allocation as in the ex post equilibrium. By the first welfare theorem, this allocation is Pareto-efficient.

Proof of Lemma 1. Concavity of the utility function (7) in consumption $x_{i}$ implies that $x_{i}$ must 
be equal for all $\theta_{i}=1$ types in the social optimum, and equal zero for all $\theta_{i}=0$ types. No waste and feasibility requires that per capita production equals per capita consumption for $\theta_{i}=1$ types, i.e., $x_{i}=\hat{x}_{i}$. Thus, the social planner determines a constant per capita investment $\hat{x}_{i}=\hat{x}$ for all $\theta=1$ types.

Because an investment $\hat{x}$ has opportunity cost of $R$ units of $c_{i}$ consumption, the budget constraint of the economy is

$$
\int\left(w_{i}-c_{i}-\theta_{i} R \hat{x}\right) d i=0 \Longleftrightarrow \int c_{i} d i=\int\left(w_{i}-\theta_{i} R \hat{x}\right) d i
$$

The planner's problem determines $\hat{x}$ to maximize total welfare,

$$
\max _{\hat{x}} \int\left(\theta_{i} x_{i}^{\alpha}+c_{i}\right) d i \text { s.t. } \int c_{i} d i=\int\left(w_{i}-\theta_{i} R \hat{x}\right) d i
$$

Substituting from the budget constraint and using $x_{i}=\hat{x}$, this is equivalent to the unconstrained problem

$$
\max _{\hat{x}} \int\left(\theta_{i} \hat{x}^{\alpha}+w_{i}-\theta_{i} R \hat{x}\right) d i .
$$

The first order necessary and sufficient condition of the concave objective is

$$
0=\int\left(\alpha \theta_{i} \hat{x}^{\alpha-1}-\theta_{i} R\right) d i \Longleftrightarrow \hat{x}=\left(\frac{\alpha}{R}\right)^{\frac{1}{1-\alpha}}
$$

where $x_{i}=\hat{x}=(\alpha / R)^{\frac{1}{1-\alpha}}$ is also the socially optimal per capita consumption for $\theta_{i}=1$ types. The corresponding efficient aggregate investment is $X=\bar{s} \hat{x}$.

In a market equilibrium, consumption choices $x_{i}(p)=(\alpha / p)^{\frac{1}{1-\alpha}}$ for $\theta_{i}=1$ types depend on market clearing price $p$, and correspond to the planner's solution if and only if aggregate investment is such that $p=R$ in every state.

\section{Proof of Proposition 2.}

i. This is a corollary of Proposition 1.

ii. From the market clearing condition (9), the market price in a state $s$ with $\bar{s}$ equals $R$ if and only if aggregate investment is $X=\bar{s}\left(\frac{\alpha}{R}\right)^{\frac{1}{1-\alpha}}$. Clearly, larger $X$ leads to lower $p$ and smaller $X$ to larger $p$ (see (9)). Suppose there was an ex post equilibrium with aggregate investment function $X(s)$ so that $p \neq R$ for some state $s$. If $p<R$, then the investment return is less than $R$ and it would be ex post optimal for some $i$ to decrease his investment and receive the safe return $R$ instead. If $p>R$, then it would be ex post optimal for some $i$ to increase investment to $\hat{x}_{i}=w_{i}$, which is feasible for some $i$ by assumption of $w_{i} \geq\left(\frac{\alpha}{R}\right)^{\frac{1}{1-\alpha}}$ for all $i$. Thus, in any ex post equilibrium, the aggregate investment function must be $X(s)=\bar{s}\left(\frac{\alpha}{R}\right)^{\frac{1}{1-\alpha}}$.

iii. (ii.) established that every ex post equilibrium has $p(s)=R$ for all $s$. Thus, Lemma 1 implies that every ex post equilibrium is efficient. In the other direction, if an equilibrium is efficient, then it has $p(s)=R$ for all $s$. Thus, every $i$ is ex post indifferent between investing and the safe return $R$, so an efficient equilibrium is an ex post equilibrium.

iv. In a first step, we will show that consumers with type $\theta_{i}=0$ do not invest in equilibrium if 
$w_{i} \geq(\alpha / R)^{1 /(1-\alpha)}$ for all $i$. In a second step, we will show that crowdinvestors with $\theta_{i}=1$ in group 1 have a larger expected investment return if and only if the average investment strategy in case of $\theta_{i}=1$ in their group is smaller (the symmetric case for group 2 holds as well). In a third step, we show that the average equilibrium investment strategy in case of $\theta_{i}=1$ must be the same in both groups, and must be the one that leads to a return of $R$ in every state.

Throughout the proof, we will use the following posterior probabilities about the state. When a consumer from the first group $(g=1)$ receives signal $\theta_{i}=1$, he receives information regarding the aggregate preference distribution in his own group, but still relies on his prior to estimate demand in the other group. Hence, he attaches the following posterior probabilities to the vector of states $\left(s_{1}, s_{2}\right)$ :

\begin{tabular}{c|cccc}
$\left(s_{1}, s_{2}\right)$ & $(\beta, \beta)$ & $(1-\beta, 1-\beta)$ & $(1-\beta, \beta)$ & $(\beta, 1-\beta)$ \\
\hline $\operatorname{Pr}\left(\left(s_{1}, s_{2}\right) \mid \theta_{i}=1, g=1\right)$ & $\frac{\beta}{2}$ & $\frac{1-\beta}{2}$ & $\frac{1-\beta}{2}$ & $\frac{\beta}{2}$
\end{tabular}

In case a consumer from group 1 receives signal $\theta_{i}=0$, the posterior probabilities are

$$
\begin{array}{c|cccc}
\left(s_{1}, s_{2}\right) & (\beta, \beta) & (1-\beta, 1-\beta) & (1-\beta, \beta) & (\beta, 1-\beta) \\
\hline \operatorname{Pr}\left(\left(s_{1}, s_{2}\right) \mid \theta_{i}=0, g=1\right) & \frac{1-\beta}{2} & \frac{\beta}{2} & \frac{\beta}{2} & \frac{1-\beta}{2}
\end{array}
$$

First step: consumers with $\theta_{i}=0$ do not invest in equilibrium. Denote the price in state $s=(\beta, \beta)$ by $p_{11}$, the price in state $s=(\beta, 1-\beta)$ by $p_{10}$ and so on. Then we can write the expected returns of crowdinvestors of type $\theta_{i}=1$ in group 1 and 2 as

$$
\begin{aligned}
& \mathbb{E}_{s}\left[p \mid \theta_{i}=1, g=1\right]=\frac{\beta}{2} p_{11}+\frac{\beta}{2} p_{10}+\frac{1-\beta}{2} p_{00}+\frac{1-\beta}{2} p_{01} \\
& \mathbb{E}_{s}\left[p \mid \theta_{i}=1, g=2\right]=\frac{\beta}{2} p_{11}+\frac{1-\beta}{2} p_{10}+\frac{1-\beta}{2} p_{00}+\frac{\beta}{2} p_{01} .
\end{aligned}
$$

Similarly, the expected returns of consumers with $\theta_{i}=0$ are

$$
\begin{aligned}
& \mathbb{E}_{s}\left[p \mid \theta_{i}=0, g=1\right]=\frac{1-\beta}{2} p_{11}+\frac{1-\beta}{2} p_{10}+\frac{\beta}{2} p_{00}+\frac{\beta}{2} p_{01} \\
& \mathbb{E}_{s}\left[p \mid \theta_{i}=0, g=2\right]=\frac{1-\beta}{2} p_{11}+\frac{\beta}{2} p_{10}+\frac{\beta}{2} p_{00}+\frac{1-\beta}{2} p_{01} .
\end{aligned}
$$

We want to show that consumers with $\theta_{i}=0$ always expect a weakly lower investment return compared to consumers with $\theta_{i}=1$. Thus, comparing $\mathbb{E}_{s}\left[p \mid \theta_{i}=1, g=2\right]$ with $\mathbb{E}_{s}\left[p \mid \theta_{i}=1, g=\right.$ $1]$,

$$
\begin{aligned}
& \mathbb{E}_{s}\left[p \mid \theta_{i}=1, g=1\right] \geq \mathbb{E}_{s}\left[p \mid \theta_{i}=0, g=2\right] \\
\Longleftrightarrow & \frac{2 \beta-1}{2} p_{11} \geq \frac{2 \beta-1}{2} p_{00} \Longleftrightarrow p_{11} \geq p_{00} .
\end{aligned}
$$

Denote the investment amount of investor $i$ if $\theta_{i}=1$ by $\hat{x}_{i}\left(\theta_{i}=1\right)$ and if $\theta_{i}=0$ by $\hat{x}_{i}\left(\theta_{i}=0\right)$. Recall that group 1 are all consumers $i \in[0,0.5]$ and group 2 are all consumers $i \in(0.5,1]$. Now we can rewrite condition (14) in terms of investment strategies. After simplifying, (14) is equivalent to

$$
\int_{0}^{0.5} \hat{x}_{i}\left(\theta_{i}=0\right) d i+\int_{0.5}^{1} \hat{x}_{i}\left(\theta_{i}=0\right) d i \geq 0
$$


which always holds true. Moreover, any positive aggregate investment by consumers with $\theta_{i}=0$ from either group leads to $\mathbb{E}_{s}\left[p \mid \theta_{i}=1, g=1\right]>\mathbb{E}_{s}\left[p \mid \theta_{i}=0, g=2\right]$. Using the same reasoning, we also get $\mathbb{E}_{s}\left[p \mid \theta_{i}=1, g=2\right] \geq \mathbb{E}_{s}\left[p \mid \theta_{i}=0, g=1\right]$, and if (15) holds with strict inequality, then $\mathbb{E}_{s}\left[p \mid \theta_{i}=1, g=2\right]>\mathbb{E}_{s}\left[p \mid \theta_{i}=0, g=1\right]$.

Note that consumers only invest if their expected return is equal to or exceeds $R$, otherwise investing at the riskless rate $R$ is a profitable deviation. Therefore, whenever consumers with $\theta_{i}=0$ from either group invest, i.e., (15) holds with strict inequality, then consumers with $\theta_{i}=$ 1 expect a return exceeding $R$. However, this cannot occur in equilibrium if $w_{i} \geq(\alpha / R)^{1 /(1-\alpha)}$ for all $i$. Suppose (15) holds with strict inequality, then it is optimal for all consumers with $\theta_{i}=1$ to increase their investment $\hat{x}_{i}\left(\theta_{i}=1\right)$ until their expected return equals $R$. For at least one consumer this deviation must be feasible, since the wealth endowment $w_{i}$ is sufficient for all consumers with $\theta_{i}=1$ to invest $\hat{x}_{i}\left(\theta_{i}=1\right)=(\alpha / R)^{1 /(1-\alpha)}$, which guarantees a return of $R$ or less. But if consumers with $\theta_{i}=1$ expect a return of $R$, then by (14), consumers with $\theta_{i}=0$ expect a return below $R$, which contradicts that (15) holds with strict inequality. Consequently, no consumer of type $\theta_{i}=0$ invests in equilibrium.

Second step: The expected return from investing if $\theta_{i}=1$ differs between both groups whenever the average investment strategy in case of $\theta_{i}=1$ differs between the groups. Suppose that there is an equilibrium where some consumers with type $\theta_{i}=1$ from group 1 (without loss of generality) invest in $x$, which implies $\mathbb{E}_{s}\left[p \mid \theta_{i}=1, g=1\right] \geq R$, otherwise not investing would be a profitable deviation. Now suppose that investors from group 2 do not invest in this case, which implies they expect a weakly lower return from investing,

$$
\begin{aligned}
& \mathbb{E}_{s}\left[p \mid \theta_{i}=1, g=1\right] \geq \mathbb{E}_{s}\left[p \mid \theta_{i}=1, g=2\right] \\
\Longleftrightarrow & \frac{2 \beta-1}{2} p_{10} \geq \frac{2 \beta-1}{2} p_{01} \Longleftrightarrow p_{10}>p_{01} .
\end{aligned}
$$

Since the aggregate demand is the same in state $s=(\beta, 1-\beta)$ and $s=(1-\beta, \beta)$, price differences between these two states must be due to differences in aggregate investment. Rewriting condition (16) in terms of investment strategies gives

$$
\begin{aligned}
& \int_{0}^{0.5}\left[\beta \hat{x}_{i}\left(\theta_{i}=1\right)+(1-\beta) \hat{x}_{i}\left(\theta_{i}=0\right)\right] d i+\int_{0.5}^{1}\left[(1-\beta) \hat{x}_{i}\left(\theta_{i}=1\right)+\beta \hat{x}_{i}\left(\theta_{i}=0\right)\right] d i \\
& \leq \int_{0}^{0.5}\left[(1-\beta) \hat{x}_{i}\left(\theta_{i}=1\right)+\beta \hat{x}_{i}\left(\theta_{i}=0\right)\right] d i+\int_{0.5}^{1}\left[\beta \hat{x}_{i}\left(\theta_{i}=1\right)+(1-\beta) \hat{x}_{i}\left(\theta_{i}=0\right)\right] d i \\
& \Longleftrightarrow \int_{0}^{0.5}\left[\hat{x}_{i}\left(\theta_{i}=1\right)-\hat{x}_{i}\left(\theta_{i}=0\right)\right] d i \leq \int_{0.5}^{1}\left[\hat{x}_{i}\left(\theta_{i}=1\right)-\hat{x}_{i}\left(\theta_{i}=0\right)\right] d i \\
& \Longleftrightarrow \int_{0}^{0.5} \hat{x}_{i}\left(\theta_{i}=1\right) d i \leq \int_{0.5}^{1} \hat{x}_{i}\left(\theta_{i}=1\right) d i,
\end{aligned}
$$

where the last line follows from the fact that consumers with $\theta_{i}=0$ do not invest in equilibrium (see first step). Thus, if a positive mass of consumers from group 1 with $\theta_{i}=1$ invest (i.e., average investment strategy in case of $\theta_{i}=1$ is $\left.\int_{0}^{0.5} \hat{x}_{i}\left(\theta_{i}=1\right) d i>0\right)$, then consumers from group 2 with $\theta_{i}=1$ must also invest $\left(\int_{0.5}^{1} \hat{x}_{i}\left(\theta_{i}=1\right) d i>0\right)$. The same reasoning holds in the opposite direction as well: If consumers from group 2 with $\theta_{i}=1$ invest, then so must those from group 1. Moreover, the expected returns of both groups are the same if and only if (17) 
holds with equality, i.e., both groups have the same aggregate investment strategy in case of $\theta_{i}=1$.

Third step: Both groups have the same aggregate investment strategy in case of $\theta_{i}=1$ that leads to $p=R$ for all $s$. From step 2, whenever the average investment strategies of the two groups in case of $\theta_{i}=1$ diverge, then so do the expected returns, which means that crowdinvestors in at least one group have a profitable deviation to either invest more or less. Thus, in equilibrium, we must have a profile of investment strategies $\left\{\hat{x}_{i}\left(\theta_{i}=1\right)\right\}_{i}$ such that

$$
\int_{0}^{0.5} \hat{x}_{i}\left(\theta_{i}=1\right) d i=\frac{1}{2}(\alpha / R)^{1 /(1-\alpha)}, \int_{0.5}^{1} \hat{x}_{i}\left(\theta_{i}=1\right) d i=\frac{1}{2}(\alpha / R)^{1 /(1-\alpha)},
$$

which leads to a an aggregate investment by group 1 of $\frac{s_{1}}{2}(\alpha / R)^{1 /(1-\alpha)}$ and by group 2 of $\frac{s_{2}}{2}(\alpha / R)^{1 /(1-\alpha)}$, which implies $p=R$ in all states and is efficient (Lemma 1).

To show (18), suppose by contradiction that $\int_{0}^{0.5} \hat{x}_{i}\left(\theta_{i}=1\right) d i>\frac{1}{2}(\alpha / R)^{1 /(1-\alpha)}$ and $\int_{0.5}^{1} \hat{x}_{i}\left(\theta_{i}=\right.$ $1) d i>\frac{1}{2}(\alpha / R)^{1 /(1-\alpha)}$, then $\mathbb{E}_{s}\left[p \mid \theta_{i}=1, g=1\right]<R$ and $\mathbb{E}_{s}\left[p \mid \theta_{i}=1, g=2\right]<R$, and not investing is a profitable deviation. Suppose $\int_{0}^{0.5} \hat{x}_{i}\left(\theta_{i}=1\right) d i<\frac{1}{2}(\alpha / R)^{1 /(1-\alpha)}$ and $\int_{0.5}^{1} \hat{x}_{i}\left(\theta_{i}=\right.$ $1) d i<\frac{1}{2}(\alpha / R)^{1 /(1-\alpha)}$, then $\mathbb{E}_{s}\left[p \mid \theta_{i}=1, g=1\right]>R$ and $\mathbb{E}_{s}\left[p \mid \theta_{i}=1, g=2\right]>R$, and investing more is profitable and feasible. Suppose $\int_{0}^{0.5} \hat{x}_{i}\left(\theta_{i}=1\right) d i>\frac{1}{2}(\alpha / R)^{1 /(1-\alpha)}$ and $\int_{0.5}^{1} \hat{x}_{i}\left(\theta_{i}=1\right) d i<\frac{1}{2}(\alpha / R)^{1 /(1-\alpha)}$, then from step 2 either $\mathbb{E}_{s}\left[p \mid \theta_{i}=1, g=1\right]<R$ or $\mathbb{E}_{s}\left[p \mid \theta_{i}=\right.$ $1, g=2]>R$, so that investing more or less is a profitable deviation. Finally, suppose $\int_{0}^{0.5} \hat{x}_{i}\left(\theta_{i}=1\right) d i<\frac{1}{2}(\alpha / R)^{1 /(1-\alpha)}$ and $\int_{0.5}^{1} \hat{x}_{i}\left(\theta_{i}=1\right) d i>\frac{1}{2}(\alpha / R)^{1 /(1-\alpha)}$, then by step 2 either $\mathbb{E}_{s}\left[p \mid \theta_{i}=1, g=1\right]>R$ or $\mathbb{E}_{s}\left[p \mid \theta_{i}=1, g=2\right]<R$.

Proof of Proposition 3. Sufficiency: If all consumers have $w_{i} \geq(\alpha / R)^{1 /(1-\alpha)}$, then Proposition 2 proves that an efficient equilibrium exists.

Necessity: To be shown: If an efficient equilibrium exists, then $w_{i} \geq(\alpha / R)^{1 /(1-\alpha)}$ for investors of both groups. In an efficient equilibrium, aggregate investment scales up linearly with the share of interested consumers in each group (Lemma 1):

$$
X(s)=\frac{s_{1}+s_{2}}{2}(\alpha / R)^{1 /(1-\alpha)} .
$$

Denote the investment amount of investor $i$ if $\theta_{i}=1$ by $\hat{x}_{i}\left(\theta_{i}=1\right)$ and if $\theta_{i}=0$ by $\hat{x}_{i}\left(\theta_{i}=0\right)$. Recall that group 1 are all consumers $i \in[0,0.5]$ and group 2 are all consumers $i \in(0.5,1]$. Now we can write aggregate investment $X$ in terms of investment strategies of all consumers,

$$
\begin{aligned}
X= & \int_{0}^{0.5}\left[s_{1} \hat{x}_{i}\left(\theta_{i}=1\right)+\left(1-s_{1}\right) \hat{x}_{i}\left(\theta_{i}=0\right)\right] d i+\int_{0.5}^{1}\left[s_{2} \hat{x}_{i}\left(\theta_{i}=1\right)+\left(1-s_{2}\right) \hat{x}_{i}\left(\theta_{i}=0\right)\right] d i \\
= & \int_{0}^{0.5}\left[s_{1}\left(\hat{x}_{i}\left(\theta_{i}=1\right)-\hat{x}_{i}\left(\theta_{i}=0\right)\right)+\hat{x}_{i}\left(\theta_{i}=0\right)\right] d i \\
& +\int_{0.5}^{1}\left[s_{2}\left(\hat{x}_{i}\left(\theta_{i}=1\right)-\hat{x}_{i}\left(\theta_{i}=0\right)\right)+\hat{x}_{i}\left(\theta_{i}=0\right)\right] d i .
\end{aligned}
$$

Since by assumption an efficient equilibrium exists, both (19) and (20) have to hold for all realizations of $\left(s_{1}, s_{2}\right)$. This is only possible if $\int_{0}^{1} \hat{x}_{i}\left(\theta_{i}=0\right) d i=0$, i.e., if consumers of type $\theta_{i}=0$ do not invest. Hence, simplifying (20) and equating aggregate investment with efficient aggregate 
investment (19), the following conditions hold in any efficient equilibrium:

$$
\begin{gathered}
2 \cdot \int_{0}^{0.5} \hat{x}_{i}\left(\theta_{i}=1\right) d i=(\alpha / R)^{1 /(1-\alpha)} \text { and } \\
2 \cdot \int_{0.5}^{1} \hat{x}_{i}\left(\theta_{i}=1\right) d i=(\alpha / R)^{1 /(1-\alpha)} .
\end{gathered}
$$

The investment budget constraint requires $\hat{x}_{i}\left(\theta_{i}=1\right) \leq w_{i}$ for all $i$. Thus, (21) implies

$$
2 \cdot \int_{0}^{0.5} w_{i} d i \geq(\alpha / R)^{1 /(1-\alpha)} \text { and } 2 \cdot \int_{0.5}^{1} w_{i} d i \geq(\alpha / R)^{1 /(1-\alpha)},
$$

and hence (since $w_{i}$ is constant in each group)

$$
w_{i} \geq(\alpha / R)^{1 /(1-\alpha)} \text { for } i \in[0,0.5] \text { and } w_{i} \geq(\alpha / R)^{1 /(1-\alpha)} \text { for } i \in(0.5,1] .
$$

Proof of Proposition 4. Consider first the case of finite $N$. Equilibrium investment by $j$ is a best response to the investment strategies of all others, so $j$ 's maximization problem is (10), which is strictly concave, so the first order condition (11) is necessary and sufficient for the maximum. Taking the expectation over $s$ on both sides of (11) and using the law of iterated expectations, we get $\mathbb{E}_{s}[p(X, s)]=R-\mathbb{E}_{s}\left[p_{X}(X, s)\right] f_{j}$. Since $p_{X}(X, s)<0$, the equilibrium investment strategies imply that the average market clearing price $p(X, s)$ larger than $R$, which is not Pareto efficient (Lemma 1).

Now consider the case $N \rightarrow \infty$, represented by a continuum of venture capital firms with measure 1. Thus, aggregate investment is then given by $X=\int_{0}^{1} f_{j} d j$. Consequently, investment by $j$ does not affect $X$. The maximization problem yields the first order condition (12) which implies $\mathbb{E}_{s}[p(X, s)]=R$. Recall that Pareto efficiency is achieved if and only if

$$
p(X, s)=\alpha\left(\frac{\left(s_{1}+s_{2}\right) / 2}{X}\right)^{1-\alpha}=R
$$

for all $s=\left(s_{1}, s_{2}\right)$. Thus, an efficient equilibrium exists if and only if venture capital firms have the necessary information to react to each change in state $s$, so that $X$ reacts to each change in $\left(s_{1}+s_{2}\right) / 2$, i.e., if and only if $\gamma=1$.

Proof of Proposition 5. For $i$ : By construction, $K$ such that $\mathbb{E}_{s}[p(K, s) \mid m]=R$ means the expected firm revenue per unit equals $R$. Thus if everything is repaid to banks - which is ensured by $r_{j}=\bar{p} \forall j$, then banks expect a repayment rate of $R$. Since banks are risk neutral, they are indifferent between lending any amount $k_{j} \geq 0$ or the outside option at rate $R$. Thus, any credit profile $\left\{k_{j}\right\}_{j=1, \ldots, N}$ which adds up to $K=K(m)$ is an equilibrium where the firm does not retain any earnings. This $K$ is unique, as larger $K$ implies $\mathbb{E}_{s}[p(K, s) \mid m]<R$, so that expected repayments to banks are less than $R$, which cannot be an equilibrium, and smaller $K$ implies $\mathbb{E}_{s}[p(K, s) \mid m]>R$, which means that the firm retains earnings (given the equilibrium requirement of zero profits for banks).

For ii.: By Lemma 1, efficiency in state $s=(\beta, \beta)$ requires an aggregate investment (credit) of $K^{*}=\beta\left(\frac{\alpha}{R}\right)^{\frac{1}{1-\alpha}}$. From the perspective of the banks, the expected firm revenue given their 
information $m$ must weakly exceed $R$ for them to be willing to provide credit, which holds if and only if

$\operatorname{Pr}(s=(\beta, \beta) \mid m) \bar{p}+2 \operatorname{Pr}(s=(\beta, 1+\beta) \mid m) p+\operatorname{Pr}((1-\beta, 1-\beta) \mid m) \underline{p} \geq R \Longleftrightarrow$

$K \leq\left(\frac{\operatorname{Pr}((\beta, \beta) \mid m) \beta^{1-\alpha}+2 \operatorname{Pr}(s=(\beta, 1-\beta) \mid m) 0.5^{1-\alpha}+\operatorname{Pr}((1-\beta, 1-\beta) \mid m)(1-\beta)^{1-\alpha}}{R \alpha^{-1}}\right)^{1 /(1-\alpha)}$.

Clearly, this condition is incompatible with $K=K^{*}$ unless $\operatorname{Pr}(s=(\beta, \beta) \mid m)=1$, which holds iff $\gamma=1$ (and $m=(\beta, \beta))$.

\section{References}

Aghion, P. And P. Bolton (1997): "A theory of trickle-down growth and development," Review of Economic Studies, 64, 151-172.

Agrawal, A., C. Catalini, and A. Goldfarb (2014): "Some Simple Economics of Crowdfunding," Innovation Policy and the Economy, 14, 63-97.

Agrawal, A. K., C. Catalini, And A. Goldfarb (2011): "The geography of crowdfunding," NBER Working Paper 16820.

Ahlers, G. K., D. Cumming, C. Günther, And D. Schweizer (2012): "Signaling in equity crowdfunding," Working Paper.

Allen, F. And D. Gale (1999): "Diversity of opinion and financing of new technologies," Journal of Financial Intermediation, 8, 68-89.

(2001): Comparing Financial Systems, MIT Press.

BanerJee, A. V. (2010): "Investment Efficiency and the Distribution of Wealth," in Equity and Growth in a Globalizing World, World Bank Publications.

Banerjee, A. V. And A. F. Newman (1993): "Occupational choice and the process of development," Journal of Political Economy, 274-298.

Belleflamme, P., T. Lambert, and A. Schwienbacher (2014): "Crowdfunding: Tapping the right crowd," Journal of Business Venturing, 29, 585-609.

Belleflamme, P., N. Omrani, and M. Peitz (2015): "The economics of crowdfunding platforms," Information Economics and Policy, 33, 11-28.

Benveniste, L. M. And P. A. Spindt (1989): "How investment bankers determine the offer price and allocation of new issues," Journal of Financial Economics, 24, 343-361.

Bergemann, D. AND J. VÄLImÄKI (2002): "Information acquisition and efficient mechanism design," Econometrica, 70, 1007-1033.

Bernstein, S., X. Giroud, And R. R. Townsend (2016): "The impact of venture capital monitoring," The Journal of Finance, 71, 1591-1622. 
Chang, J.-W. (2015): "The economics of crowdfunding," working paper.

Chemla, G. And K. Tinn (2016): "Learning through crowdfunding," working paper.

Crowdexpert (2015): "Massolution Crowdfunding Industry 2015 Report," http:// crowdexpert.com/crowdfunding-industry-statistics/, Last accessed 14/01/2018.

Dasgupta, P. And E. Maskin (2000): "Efficient auctions," Quarterly Journal of Economics, $341-388$.

Davies, J. B., S. Sandström, A. Shorrocks, and E. N. Wolff (2011): "The Level and Distribution of Global Household Wealth," Economic Journal, 121, 223-254.

De Mesa, D. And D. C. Webb (1992): "Efficient credit rationing," European Economic Review, $36,1277-1290$.

Diamond, D. W. (1984): "Financial intermediation and delegated monitoring," The Review of Economic Studies, 51, 393-414.

Ellman, M. And S. Hurkens (2015): "Optimal crowdfunding design," working paper.

European Startup Monitor (2016): "European Startup Monitor," http:// europeanstartupmonitor.com/, Last accessed 5/7/2017.

Financial Times (2016): "Investors reassess political risks after Brexit," https://www.ft.com/ content/9cc65980-3dfc-11e6-8716-a4a71e8140b0, Last accessed 30/11/2016.

ForTune (2014): "Why investors are pouring millions into crowdfunding," http://fortune.com/ 2014/04/17/why-investors-are-pouring-millions-into-crowdfunding.

Fundable (2013): "Startup funding: A look at the top sources of startup funding," https: //www.fundable.com/infographics/startup-funding, Last accessed 9/6/2017.

(2016): "How is Equity Crowdfunding Different?" https://www.fundable.com/learn/ resources/guides/crowdfunding-guide/equity-crowdfunding, Last accessed 10/12/2016.

Gailmard, S. and T. R. Palfrey (2005): "An experimental comparison of collective choice procedures for excludable public goods," Journal of Public Economics, 89, 1361-1398.

Galor, O. And J. ZeIra (1993): "Income distribution and macroeconomics," Review of Economic Studies, 60, 35-52.

Grossman, S. J. And J. E. Stiglitz (1980): "On the impossibility of informationally efficient markets," American Economic Review, 70, 393-408.

GrüneR, H. P. (2003): "Redistribution as a selection device," Journal of Economic Theory, 108, 194-216.

(2008): "Capital markets, information aggregation and inequality: theory and experimental evidence," CEPR Discussion Paper 6750. 
Grüner, H. P. AND R. Schils (2007): "The Political Economy of Wealth and Interest," Economic Journal, 117, 1403-1422.

GuARDIAN (2014): "How we achieved business success through crowdfunding," https://www.theguardian.com/small-business-network/2014/oct/17/ business-success-through-crowdfunding, Last accessed 30/11/2016.

HANDELSBlatT (2009): "Escada-Verkauf: Freudentraenen und Kritik nach Mittal-Uebernahme," http://www.handelsblatt.com/unternehmen/industrie/ escada-verkauf-freudentraenen-und-kritik-nach-mittal-uebernahme/3297708.html, Last accessed 30/11/2016.

- (2015): "Personalabbau bei Escada: Luxuslabel streicht 200 Stellen," http://www.handelsblatt.com/unternehmen/handel-konsumgueter/ personalabbau-bei-escada-luxuslabel-streicht-200-stellen/12397198.html, Last accessed 30/11/2016.

Li, E. AND J. S. MARTin (2014): "Reputation acquisition in capital formation: An empirical investigation," Working Paper, University of Melbourne.

Massolution (2015): "2015CF Crowdfunding Industry Report," http://reports . crowdsourcing .org/index . php?route=product/product\&product_id=54.

Mollick, E. (2014): "The dynamics of crowdfunding: An exploratory study," Journal of Business Venturing, 29, 1-16.

Ottaviani, M. And P. N. Sørensen (2009): "Surprised by the parimutuel odds?" American Economic Review, 99, 2129-2134.

PiketTy, T. (1997): "The dynamics of the wealth distribution and the interest rate with credit rationing," Review of Economic Studies, 64, 173-189.

(2014): Capital in the Twenty-first Century, Harvard University Press.

Roth, A. E. And A. Ockenfels (2002): "Last minute bidding and the rules for ending second price auctions: evidence from ebay and amazon auctions on the internet," American Economic Review, 92, 1093-1103.

Saez, E. And G. Zucman (2014): "Wealth inequality in the United States since 1913: Evidence from capitalized income tax data," NBER Working Paper 20625.

Schwienbacher, A. (2015): "Entrepreneurial Risk-Taking in Crowdfunding Campaigns," working paper.

Statista (2017): "Digital Market Outlook," https://www.statista.com/outlook/297/100/ alternative-financing/worldwide.

Strausz, R. (2016): "A Theory of Crowdfunding-a mechanism design approach with demand uncertainty and moral hazard," working paper. 
Tirole, J. (2006): The Theory of Corporate Finance, Princeton University Press.

Wolff, E. N. (2002): Top heavy: The increasing inequality of wealth in America and what can be done about it, New Press. 